Research Article

\title{
Evaluation of Structural Properties and Catalytic Activities in Knoevenagel Condensation Reaction of Zeolitic Imidazolate Framework-8 Synthesized under Different Conditions
}

\author{
Pham Dinh Du $\mathbb{D}^{1}{ }^{1}$ Nguyen Viet Duy Thanh, ${ }^{2}$ and Nguyen Trung Hieu ${ }^{3}$ \\ ${ }^{1}$ Faculty of Natural Science, Thu Dau Mot University, Thu Dau Mot 820000, Vietnam \\ ${ }^{2}$ Center for Vocational Education and Continuing Education, Can Tho 900000, Vietnam \\ ${ }^{3}$ Center for Scientific Research and Practice, Thu Dau Mot University, Thu Dau Mot 820000, Vietnam \\ Correspondence should be addressed to Pham Dinh Du; dupd@tdmu.edu.vn
}

Received 27 December 2018; Accepted 21 March 2019; Published 17 April 2019

Guest Editor: Hien Duy Mai

Copyright $(92019$ Pham Dinh Du et al. This is an open access article distributed under the Creative Commons Attribution License, which permits unrestricted use, distribution, and reproduction in any medium, provided the original work is properly cited.

In the present study, the zeolitic imidazolate framework-8 (ZIF-8) was synthesized at both room temperature and high temperatures. The effects of solvents, molar ratios of precursors, reaction time, and temperature on the structural properties of the asprepared materials were investigated. Moreover, the surface morphologies of the obtained specimens were characterized using $\mathrm{X}$-ray diffraction, scanning electron microscopy, Fourier-transform infrared spectroscopy, and nitrogen adsorption methods. The results show that ZIF-8 was formed in methanol and water at room temperature and in dimethylformamide (DMF) at high temperatures. Further, in methanol, the molar ratios of precursors and reaction time have negligible effects on the morphologies and structures of ZIF-8; however, in DMF, the reaction temperature has a significant influence on the microstructures of ZIF-8. The catalytic activities of the obtained materials were evaluated using the Knoevenagel condensation reaction, and ZIF- 8 proves to be an excellent solid base catalyst.

\section{Introduction}

Zeolitic imidazolate frameworks (ZIFs) belong to the family of metal-organic frameworks (MOFs) and possess unique properties (uniform small pores and high surface area) of both zeolites and MOFs [1, 2]. In ZIFs, divalent metal cations are found to be tetrahedrally coordinated with the imidazolate anions $[2,3]$. In recent years, ZIFs have attracted significant attention in gas storage and separation applications $[4,5]$, catalytic reactions [6], chemical processes $[7,8]$, and drug delivery systems [9]. ZIF-8 is one of the most studied zeolitic imidazolate frameworks due to its high chemical and thermal stabilities. In addition, ZIF- 8 has a large surface area $\left(S_{\mathrm{BET}}=1630 \mathrm{~m}^{2} \cdot \mathrm{g}^{-1}\right)$ and high porosity $\left(0.636 \mathrm{~cm}^{3} \cdot \mathrm{g}^{-1}\right)$ [2]. In previous studies, ZIF-8 is synthesized in DMF at high temperature and pressure [2, 3]. ZIF-8 can also be synthesized in methanol at room temperature under normal pressure $[2,10-14]$. In these two approaches, the solvents and temperature/pressure have a critical role in the formation of ZIF-8. However, there have not been any studies dealing with this issue.

The Knoevenagel condensation is an important reaction for the formation of carbon-carbon double bonds. The reaction is traditionally catalyzed by conventional bases such as $\mathrm{KOH}, \mathrm{NaOH}$, or amine compounds [15]. Today, many researchers have conducted this reaction with different precursors by using solid base catalysts to expand their applicability in the organic synthesis industry [16-18]. Recently, Tran et al. [19] have studied the catalytic activity of ZIF-8 by the Knoevenagel condensation reaction and advocated its feasibility as a catalyst.

In the present work, ZIF-8 was synthesized in two different routes. The effects of solvents, molar ratios of precursors, reaction time, and temperature on the structural properties of the as-prepared materials were investigated. In addition, the catalytic activities of the fabricated materials 
were evaluated using the Knoevenagel condensation reaction.

\section{Experimental}

2.1. Synthesis and Characterization of ZIF-8. ZIF-8 was synthesized via two different routes using zinc nitrate hexahydrate $\left(\mathrm{Zn}\left(\mathrm{NO}_{3}\right)_{2} \cdot 6 \mathrm{H}_{2} \mathrm{O}\right.$, Fisher) and 2-methylimidazole $\left(\mathrm{C}_{4} \mathrm{H}_{6} \mathrm{~N}_{2}, 99 \%\right.$, Acros) (denoted as meIm) precursors.

(i) Process $\mathrm{A}$ was performed according to $\mathrm{Zhu}$ et al. [20]. In a typical process, $8 \mathrm{mmol} \mathrm{Zn}\left(\mathrm{NO}_{3}\right)_{2} \cdot 6 \mathrm{H}_{2} \mathrm{O}$ was dissolved in $1.4 \mathrm{~mol}$ methanol $\left(\mathrm{CH}_{3} \mathrm{OH}, 99.9 \%\right.$, Fisher) (denoted as $\mathrm{MeOH}$ ) (solution 1) and $64.4 \mathrm{mmol}$ meIm was dissolved in $1.4 \mathrm{~mol} \mathrm{MeOH}$ (solution 2). Solution 2 was then added to solution 1 , and the as-prepared mixture was stirred for $8 \mathrm{~h}$. Finally, the obtained ZIF- 8 powder (denoted as $\mathrm{Z}-\mathrm{A}(\mathrm{MeOH})$ ) was collected using centrifugation at $3000 \mathrm{rpm}$, washed three times with $\mathrm{MeOH}$, and dried overnight at $100^{\circ} \mathrm{C}$.

(ii) Process $\mathrm{B}$ was carried out according to Bushell et al. [21]. In a typical process, $7.20 \mathrm{~g} \mathrm{Zn}\left(\mathrm{NO}_{3}\right)_{2} \cdot 6 \mathrm{H}_{2} \mathrm{O}$ and $4.48 \mathrm{~g}$ meIm were first dissolved in $90 \mathrm{~mL}$ dimethylformamide $\left(\mathrm{C}_{3} \mathrm{H}_{7} \mathrm{NO}, \geq 99.5 \%\right.$, Fisher $)$ (denoted as DMF) and the prepared solution was then heated in a Teflon-lined steel autoclave (volume of $200 \mathrm{~mL}$ ) for three days at $100^{\circ} \mathrm{C}$. The asproduced white solid material was collected using filtration, washed in a Soxhlet apparatus for two days with $\mathrm{MeOH}$, and dried at $100^{\circ} \mathrm{C}$ to obtain ZIF8 (denoted Z-B(DMF)).

The effects of solvents, molar ratios of $\mathrm{Zn}\left(\mathrm{NO}_{3}\right)_{2} \cdot 6 \mathrm{H}_{2} \mathrm{O}$ and meIm, reaction time, and temperature on the structural properties of the as-prepared ZIF-8 samples were further studied.

Characterization. X-ray diffraction (XRD) patterns were recorded on a VNU-D8 Advance Instrument (Bruker, Germany) under- $\mathrm{Cu} \mathrm{K} \alpha$ radiation $(\lambda=1.5418 \AA)$. The $\mathrm{N}_{2}$ adsorption/desorption isotherm measurement test was performed at $77 \mathrm{~K}$ in a Tristar 3000 analyzer, and before setting the dry mass, the samples were degassed at $250^{\circ} \mathrm{C}$ with $\mathrm{N}_{2}$ for $5 \mathrm{~h}$. Scanning electron microscopy (SEM) images were obtained using an SEM JMS-5300LV (Japan), and infrared spectra (IR) were recorded in a Jasco FT/IR-4600 spectrometer (Japan) in the range of $4000-400 \mathrm{~cm}^{-1}$.

2.2. Knoevenagel Reaction. The Knoevenagel condensation reaction between benzaldehyde and ethyl cyanoacetate was carried out according to Martins et al. [18]. In the reaction, $1.07 \mathrm{~g}(10 \mathrm{mmol})$ benzaldehyde $\left(\mathrm{C}_{6} \mathrm{H}_{5} \mathrm{CHO}, 98 \%\right.$, Acros), $1.04 \mathrm{~g}(10 \mathrm{mmol})$ ethyl cyanoacetate $\left(\mathrm{NCCH}_{2} \mathrm{CO}_{2} \mathrm{C}_{2} \mathrm{H}_{5}\right.$, $98 \%$, Acros), and $15.42 \mathrm{~g}$ toluene $\left(\mathrm{C}_{6} \mathrm{H}_{5} \mathrm{CH}_{3}, 99.9 \%\right.$, Duksan) were added to a glass reactor and stirred at $30^{\circ} \mathrm{C}$. When the temperature became stable, $0.1 \mathrm{~g}$ of ZIF- 8 was added. After $6 \mathrm{~h}$ of reaction, the solution was centrifuged to remove the catalyst. The compositional analysis of the reactants and products in the liquid sample was executed using a GC-MS chromatograph (Agilent GC-MS 7890).

The conversion and the selectivity were calculated according to the following equations:

$$
\begin{aligned}
\text { conversion }(\%)= & \frac{\text { moles of reacted benzaldehyde }}{\text { moles of initial benzaldehyde }} \times 100, \\
\text { selectivity }(\%)= & \frac{\% \text { product of ethyl-2-cyano-3-phenylacrylate }}{\% \text { total products }} \\
& \times 100 .
\end{aligned}
$$

\section{Results and Discussion}

3.1. Structural Properties of $Z-A(M e O H)$ and $Z-B(D M F)$. Figure 1(a) exhibits the XRD patterns of ZIF- 8 synthesized with process $A$ and process $B$. The diffraction peak (011) at $2 \theta=7.2^{\circ}$ is observed in both samples, indicating their high crystallinities $[2,10,12,20,22]$. However, the intensity of diffraction peaks in $\mathrm{Z}-\mathrm{B}(\mathrm{DMF})$ is higher than that in $\mathrm{Z}-\mathrm{A}(\mathrm{MeOH})$, and this means that $\mathrm{Z}-\mathrm{B}(\mathrm{DMF})$ has higher symmetric planes.

The FT-IR spectra of both Z-A(MeOH) and Z-B(DMF) are displayed in Figure 1(b), and the findings are consistent with earlier reported results $[19,23,24]$. The bands at $3122 \mathrm{~cm}^{-1}$ and $2920 \mathrm{~cm}^{-1}$ are associated with the aromatic and the aliphatic $\mathrm{C}-\mathrm{H}$ asymmetric stretching vibrations, respectively. The band at $1668 \mathrm{~cm}^{-1}$ is attributed to the $\mathrm{C}=\mathrm{C}$ stretching mode, and the band at $1574 \mathrm{~cm}^{-1}$ is assigned to the $\mathrm{C}=\mathrm{N}$ stretching mode. The bands at $1300-1460 \mathrm{~cm}^{-1}$ are associated with the entire ring stretching, whereas the band at $1140 \mathrm{~cm}^{-1}$ is formed from the aromatic C-N stretching mode. Similarly, the bands at $991 \mathrm{~cm}^{-1}$ and $748 \mathrm{~cm}^{-1}$ could be assigned to the $\mathrm{C}-\mathrm{N}$ bending vibration mode and to the $\mathrm{C}-\mathrm{H}$ bending mode, respectively. Moreover, the band at $690 \mathrm{~cm}^{-1}$ is developed due to the ring out-of-plane bending vibration of imidazolate. The sharp band at $416 \mathrm{~cm}^{-1}$ formed due to $\mathrm{Zn}-\mathrm{N}$ stretching indicates that zinc atoms are connected to the nitrogen atoms in the 2-methylimidazolate linkers.

The surface morphologies of the materials synthesized with the two approaches are totally different. $\mathrm{Z}-\mathrm{A}(\mathrm{MeOH})$ comprises cubic crystals, hexagonal-faceted crystals, and rhombic dodecahedrons (with an edge of $\sim 100 \mathrm{~nm}$ ) (Figures 2(a) and 2(b)). In contrast, Z-B(DMF) has truncated rhombic dodecahedrons with varying particle sizes of 3-20 $\mu \mathrm{m}$ (Figures 2(c) and 2(d)) [19, 22, 25]. Hence, compared with $\mathrm{Z}-\mathrm{A}(\mathrm{MeOH}), \mathrm{Z}-\mathrm{B}(\mathrm{DMF})$ yields high and sharp diffraction peaks due to its clear crystal planes and large crystal size.

In process $A$, the formation path of ZIF- 8 depends on the reaction time $[10,11]$. However, in process $B$, ZIF- 8 was prepared in $\mathrm{DMF}$ at $100^{\circ} \mathrm{C}$ in three days; hence, a fully crystalline ZIF-8 phase was obtained.

Figure 3 displays the nitrogen adsorption/desorption isotherms of $\mathrm{Z}-\mathrm{A}(\mathrm{MeOH})$ sample and $\mathrm{Z}-\mathrm{B}(\mathrm{DMF})$ sample at $77 \mathrm{~K}$. According to the classification of IUPAC, the isotherm curves belong to type-I, indicating that $\mathrm{Z}-\mathrm{A}(\mathrm{MeOH})$ and $\mathrm{Z}-\mathrm{B}(\mathrm{DMF})$ are microporous materials. The specific 


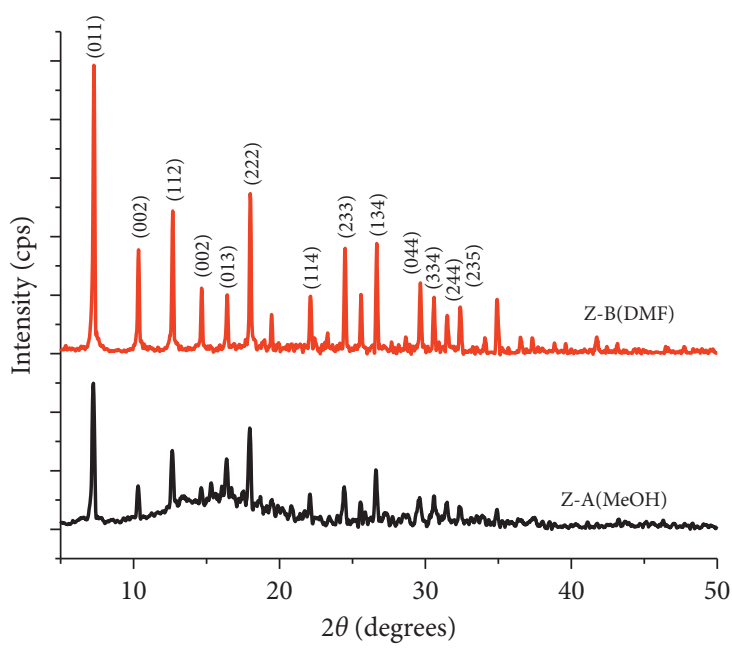

(a)

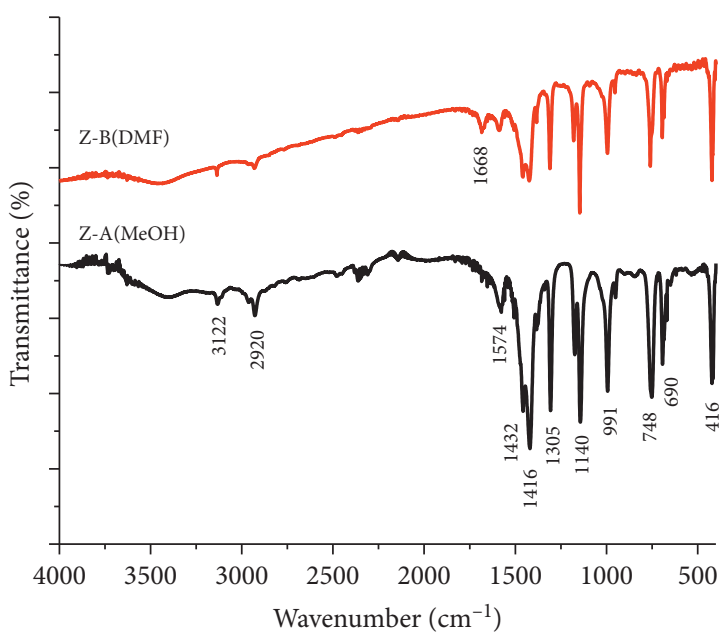

(b)

Figure 1: (a) XRD patterns and (b) FT-IR spectra of Z-A(MeOH) and Z-B(DMF) samples.

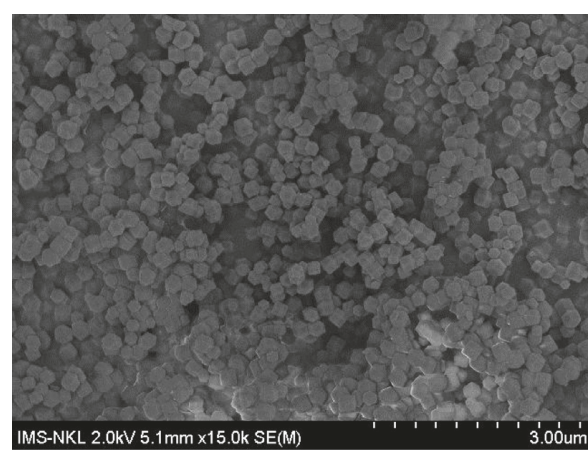

(a)

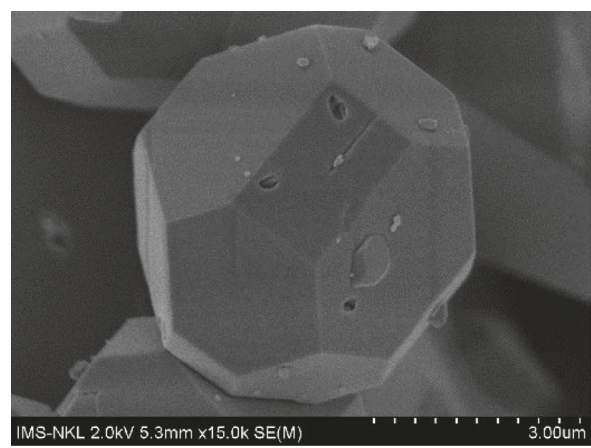

(c)

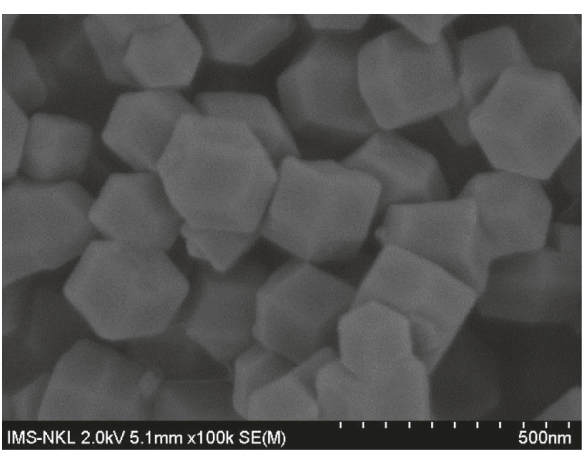

(b)

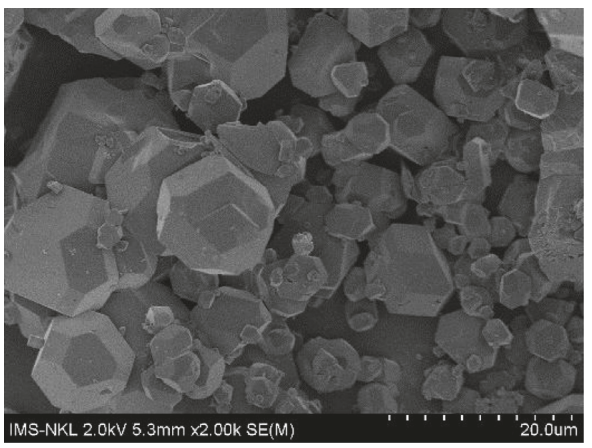

(d)

Figure 2: SEM images of Z-A(MeOH) $(a, b)$ and $\mathrm{Z}-\mathrm{B}(\mathrm{DMF})(\mathrm{c}, \mathrm{d})$.

surface area of $\mathrm{Z}-\mathrm{A}(\mathrm{MeOH})$ and $\mathrm{Z}-\mathrm{B}(\mathrm{DMF})$ is $1279 \mathrm{~m}^{2} \cdot \mathrm{g}^{-1}$ and $1415 \mathrm{~m}^{2} \cdot \mathrm{g}^{-1}$, respectively (Table 1 ). These values are higher than those of ZIF-8 synthesized with other routes $[23,26]$.

3.2. Effects of Solvents. Solvents play an important role in the ZIF-8 synthesis. Earlier studies reported that ZIF-8 can be formed in different solvents: $\operatorname{DMF}[19,21]$, methanol [2, 10-14], and water [25]. Therefore, in our experiment, the effects of different solvents (methanol, DMF, water, and toluene) on the ZIF- 8 formation were investigated in detail.
Table 2 describes the characteristics of ZIF- 8 obtained from process $\mathrm{A}$ and process $\mathrm{B}$ with different solvents.

It is clear that toluene is an unsuitable solvent for the ZIF-8 synthesis. This can be attributed to the very small dipole moment of toluene $(0.36 \mathrm{D})$ compared with that of methanol $(1.69 \mathrm{D})$, water $(1.85 \mathrm{D})$, and DMF $(3.86 \mathrm{D})$, and the deprotonation of a meIm compound cannot occur to form a meIm ${ }^{-}$ion.

Figure 4 shows that the synthesized samples in water have characteristic diffraction peaks (at $2 \theta<30^{\circ}$ ) and 


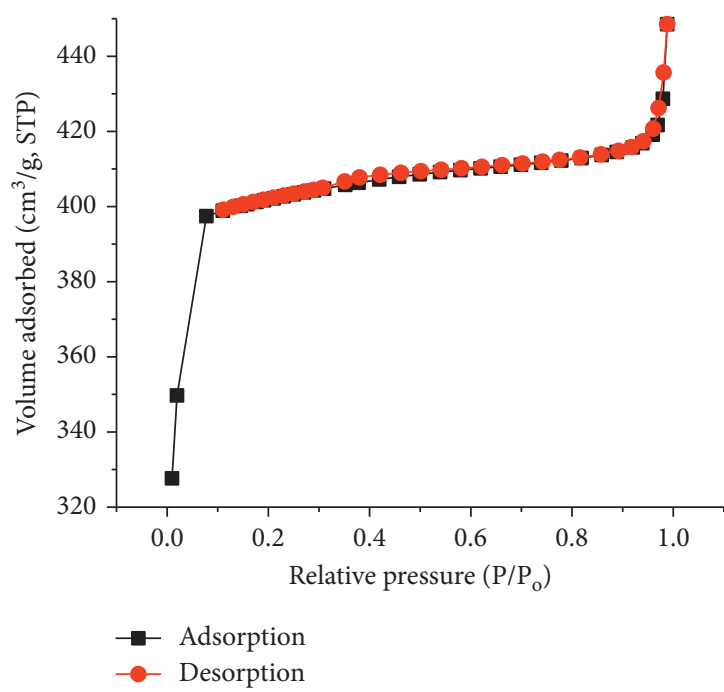

(a)

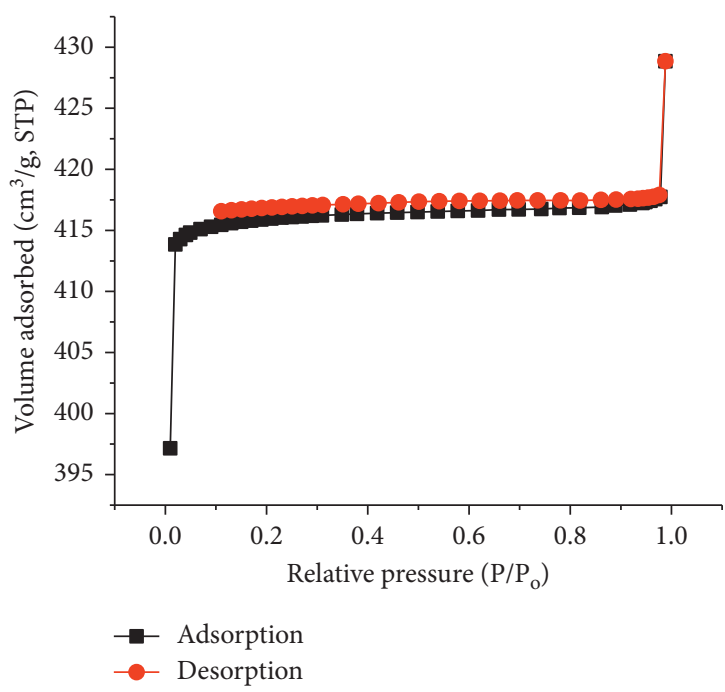

(b)

Figure 3: Nitrogen adsorption/desorption isotherms of Z-A(MeOH) sample (a) and Z-B(DMF) sample (b).

TABle 1: Porous properties of ZIF-8 samples.

\begin{tabular}{lcccc}
\hline Sample & $\begin{array}{c}\text { BET surface area } \\
\left(\mathrm{m}^{2} \cdot \mathrm{g}^{-1}\right)\end{array}$ & $\begin{array}{c}\text { t-plot micropore } \\
\text { area }\left(\mathrm{m}^{2} \cdot \mathrm{g}^{-1}\right)\end{array}$ & $\begin{array}{c}\text { t-plot external surface } \\
\text { area }\left(\mathrm{m}^{2} \cdot \mathrm{g}^{-1}\right)\end{array}$ & $\begin{array}{c}\text { t-plot micropore } \\
\text { volume }\left(\mathrm{cm}^{3} \cdot \mathrm{g}^{-1}\right)\end{array}$ \\
\hline $\mathrm{Z}-\mathrm{A}(\mathrm{MeOH})$ & 1279 & 1237 & 42 & 0.604 \\
$\mathrm{Z}-\mathrm{B}(\mathrm{DMF})$ & 1415 & 1412 & 3 & 0.642 \\
\hline
\end{tabular}

TABLE 2: Characteristics of ZIF-8 obtained in different solvents.

\begin{tabular}{lcc}
\hline Solvent & \multicolumn{2}{c}{ Product (state, color, and abundance ratio) } \\
& Process A & Process B \\
\hline Methanol & Solid, white, medium* & Solid, milk white, very small \\
DMF & Gel, white & Solid, white, medium ${ }^{* *}$ \\
Water & Solid, white, large & Solid, white, large \\
Toluene & Solid, gray, very small & Gel, white \\
\hline
\end{tabular}

${ }^{*} \mathrm{Z}-\mathrm{A}(\mathrm{MeOH})$ sample; ${ }^{*} \mathrm{Z}-\mathrm{B}(\mathrm{DMF})$ sample.

characteristic vibration bands. However, in process $\mathrm{B}$, the diffraction peaks at $2 \theta=31.73^{\circ}, 34.4^{\circ}, 36.23^{\circ}$, and $47.48^{\circ}$ and the band at $492 \mathrm{~cm}^{-1}$ indicate the existence of $\mathrm{ZnO}$ oxides and $\mathrm{Zn}-\mathrm{O}$ bonds in ZIF-8 [26]. This can be ascribed to the hydrolysis of $\mathrm{Zn}^{2+}$ ions in water at high temperatures.

The morphologies of the synthesized samples in water are displayed in Figure 5. In process A, the surface morphologies of ZIF-8 are indeterminate (Figures 5(a) and 5(b)). On the contrary, the microstructures of ZIF- 8 synthesized in process $B$ consist of hexagonal cylinders and cubic crystals (Figures 5(c) and 5(d)).

The results in Table 2 indicate that the solvent exchange between the two processes did not lead to the formation of ZIF-8. This is due to large differences in the boiling temperature and dipole moment of the solvents, indicating that solvents play an important role in the synthesis of ZIF-8.

\subsection{Effects of Synthesis Time and meIm/Zn Molar Ratios.} Figure 6 displays the SEM images of the synthesized ZIF-8 samples at two different stirring intervals - two days and five days. Both samples have mainly hexagonal and rhombic dodecahedron crystals of a diameter of $\sim 100 \mathrm{~nm}$. Further, their very sharp diffraction peaks appear at $2 \theta$ below $10^{\circ}$, indicating the formation of highly crystalline materials (Figure $7(\mathrm{a})$ ).

The XRD patterns of the samples synthesized at different meIm/Zn molar ratios are presented in Figure $7(\mathrm{~b})$. In all cases, the amounts of $\mathrm{Zn}\left(\mathrm{NO}_{3}\right)_{2} \cdot 6 \mathrm{H}_{2} \mathrm{O}$ and methanol were kept constant. No conspicuous difference was noticed in the XRD peaks of the samples; however, their relative crystallinities slightly decrease as the $\mathrm{meIm} / \mathrm{Zn}$ molar ratio increases from $64.4 / 8$ to $100 / 8$. These findings are well consistent with those reported by Zhang et al. [24].

3.4. Effects of Synthesis Temperature. The effects of reaction temperature on ZIF-8 synthesized with the process B are depicted in Figure 8. Noticeably, better cohesion of particles in the sample synthesized at $200^{\circ} \mathrm{C}$ reduces the intensities of diffraction peaks at larger angles. However, as the reaction temperature increases, the intensities of diffraction peaks at angles less than $10^{\circ}$ become higher, indicating the formation of ZIF-8 with higher crystallinities.

In conclusion, the meIm/Zn molar ratios, reaction time, and temperature have an impact on the crystallinity of ZIF-8 but do not affect its crystalline structure.

3.5. Catalytic Test. The Knoevenagel condensation reaction between benzaldehyde and ethyl cyanoacetate to form ethyl- 


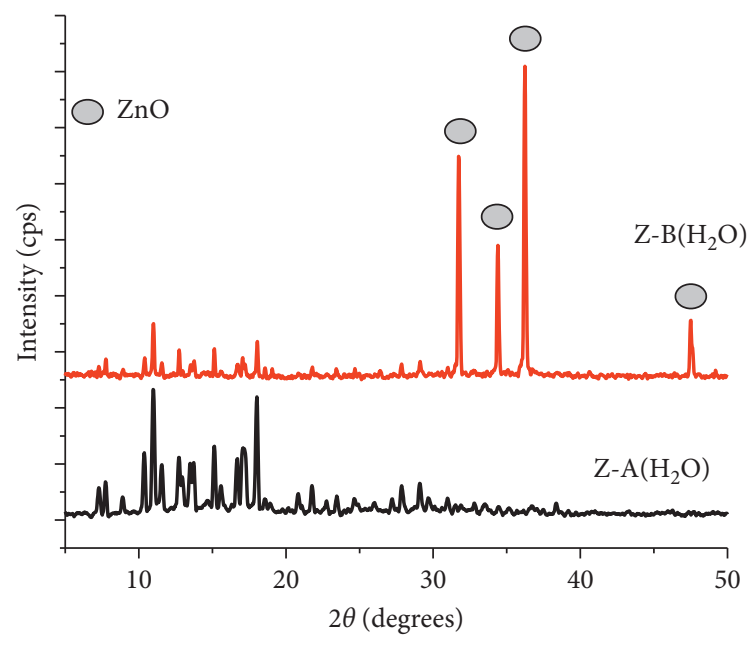

(a)

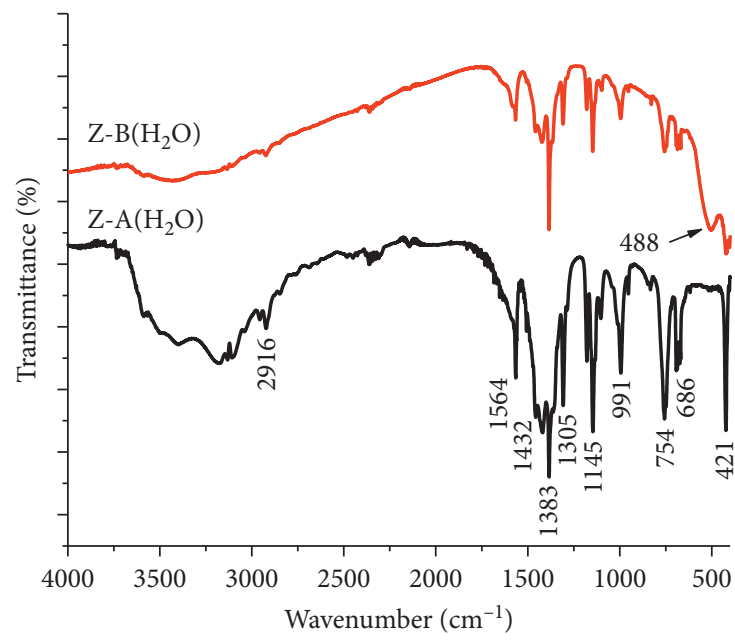

(b)

FIGURE 4: (a) XRD patterns and (b) FT-IR spectra of ZIF-8 synthesized in water.

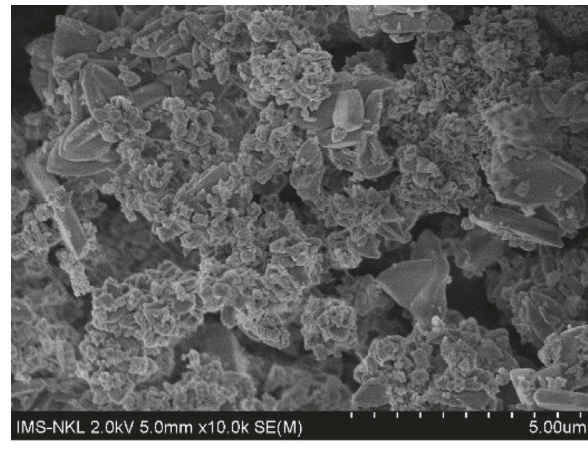

(a)

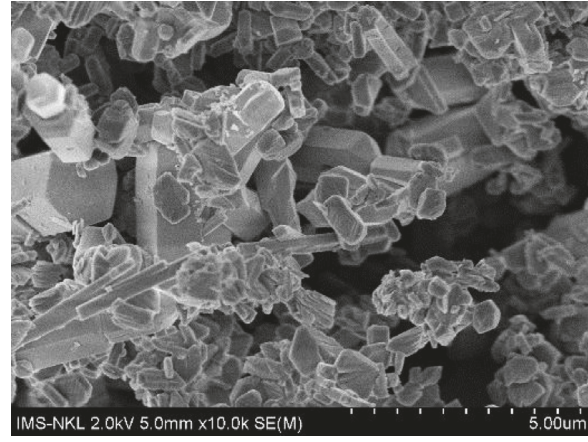

(c)

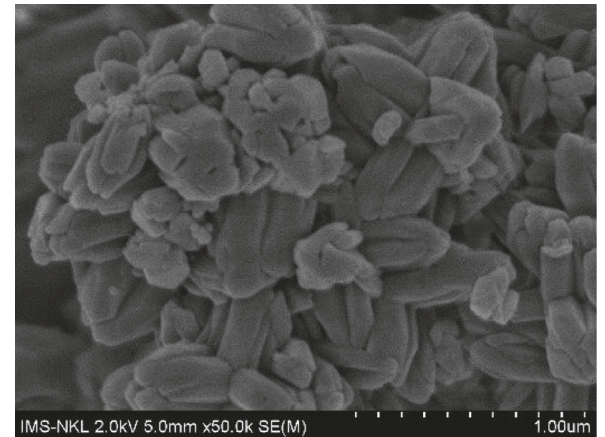

(b)

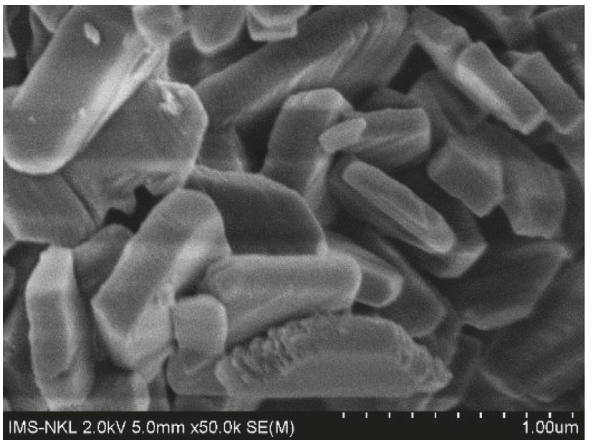

(d)

Figure 5: SEM of ZIF-8 synthesized in water: process A (a, b); process B (c, d).

2-cyano-3-phenylacrylate (Scheme 1) was used to test the catalytic activities of the synthesized ZIF-8 samples.

The effect of different ZIF-8 samples on the Knoevenagel condensation reaction is illustrated in Figure 9. Evidently, all synthesized samples exhibit excellent catalytic activities in the Knoevenagel condensation reaction (the benzaldehyde conversion in the catalytic reactions is considerably higher than that in the reactions without catalysts). Figure 9(a) shows that the conversion of benzaldehyde depends on the crystallinity of ZIF-8. The conversion is greater when the intensity of diffraction peaks at $2 \theta<10^{\circ}$ is higher (Figures 1(a), 7(a), and 8(b)). Specifically, ZIF-8 synthesized with process $B$ at $200^{\circ} \mathrm{C}$ has the highest yield. In addition, the selectivity of ethyl-2-cyano-3-phenylacrylate always remains close to $100 \%$ (Figure 9(b)), indicating that the formation of benzoic acid during the catalytic reaction is negligible.

The Knoevenagel condensation reaction is commonly catalyzed by liquid or solid bases. ZIF-8 is a bifunctional catalyst composed of both acidic (Lewis acid $\mathrm{Zn}^{2+}$ ions) and basic sites (imidazole groups) [20]. It was noticed that the 


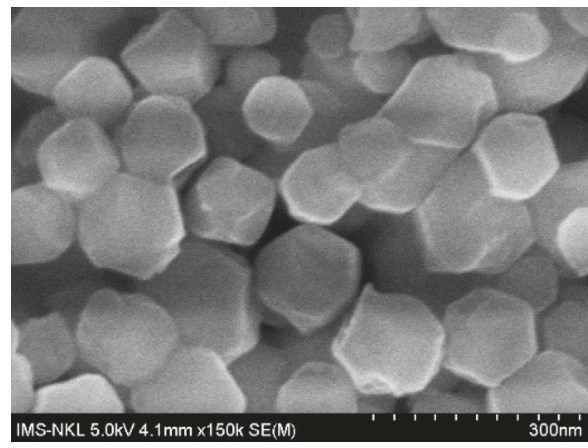

(a)

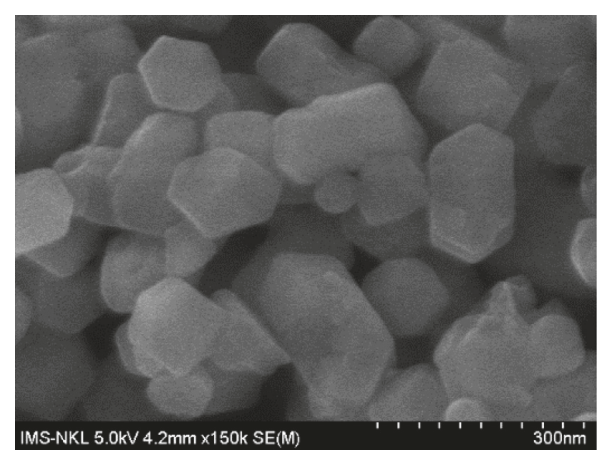

(b)

Figure 6: SEM images of ZIF-8 crystals synthesized with process A as a function of synthesis time: (a) two days; (b) five days.

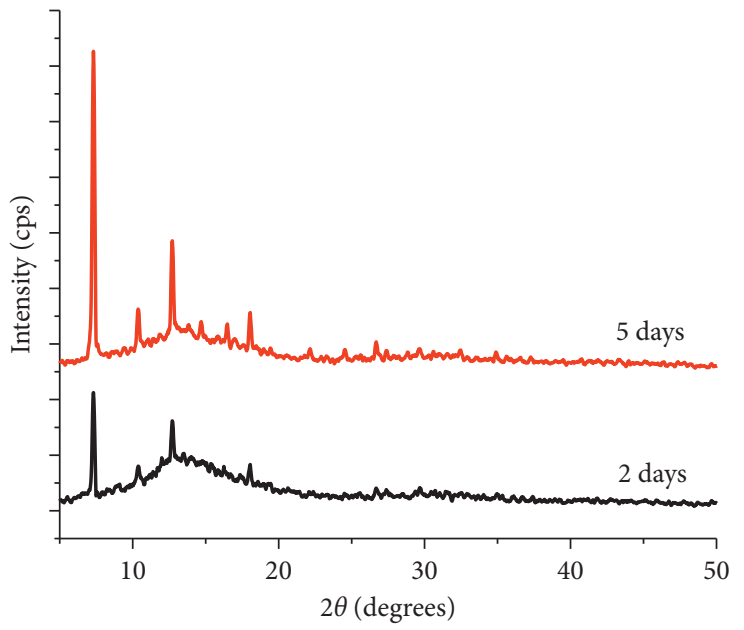

(a)

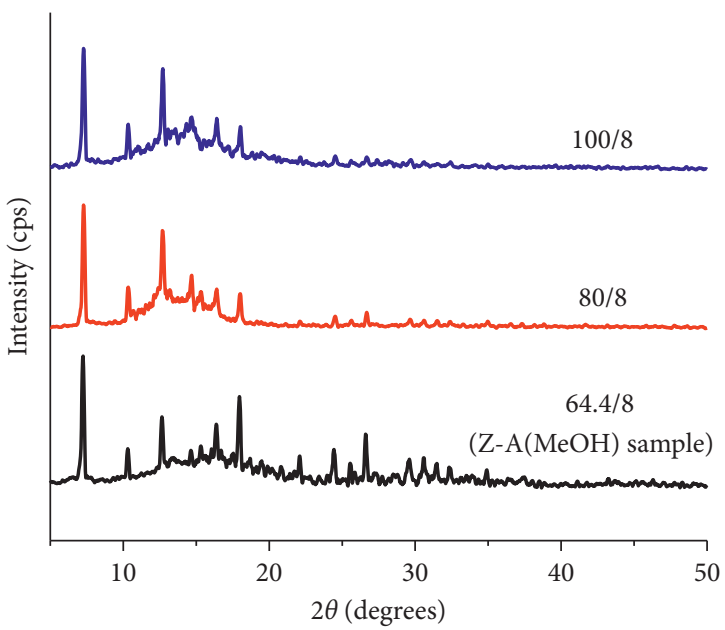

(b)

FIGURE 7: XRD patterns of ZIF-8 crystals synthesized with process A: (a) different synthesis times; (b) different meIm/Zn molar ratios.

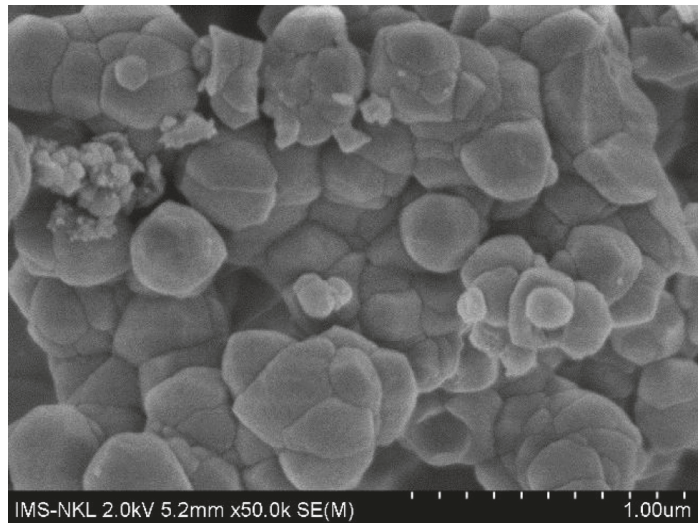

(a)

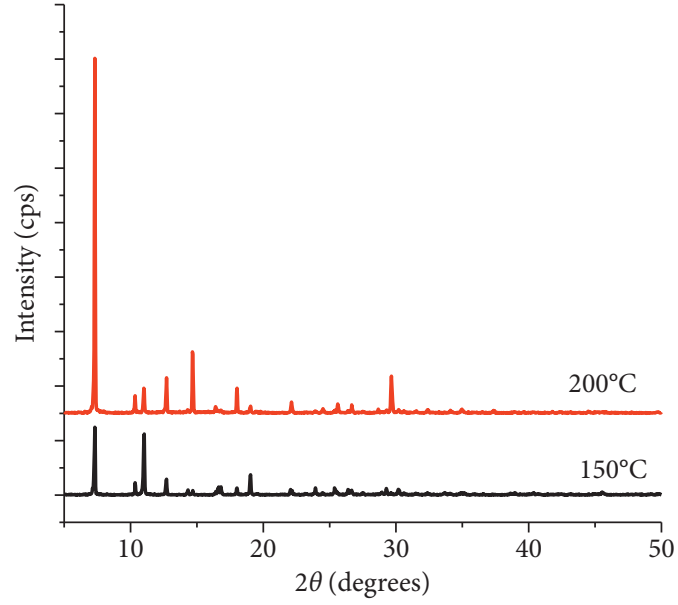

(b)

FIgURE 8: SEM image (a) and XRD patterns (b) of ZIF-8 samples synthesized with process B at different temperatures.

catalytic activities of ZIF- 8 are governed by the basic sites of imidazoles. To evaluate the durability of ZIF-8 catalyst for the Knoevenagel reaction, Tran et al. also test the leaching of the 2-methylimidazole linker [19]. They conclude that the ZIF-8 solid catalysts remain stable, and no contribution of homogeneous catalysis due to active acid species leaching 


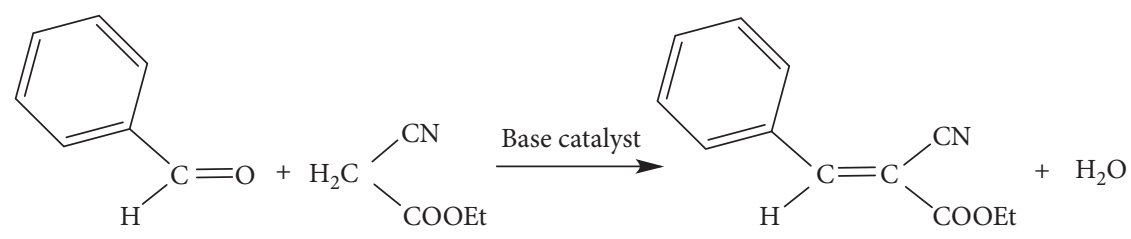

Scheme 1: Knoevenagel condensation reaction between benzaldehyde and ethyl cyanoacetate.

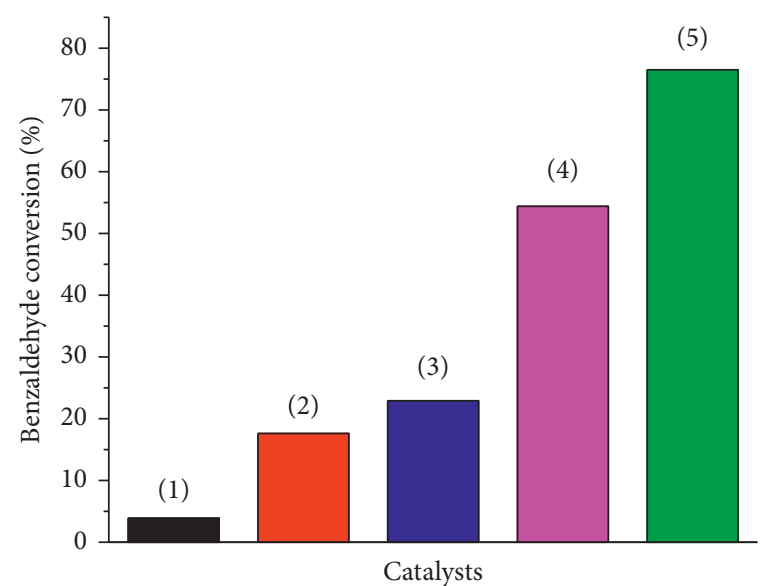

(a)

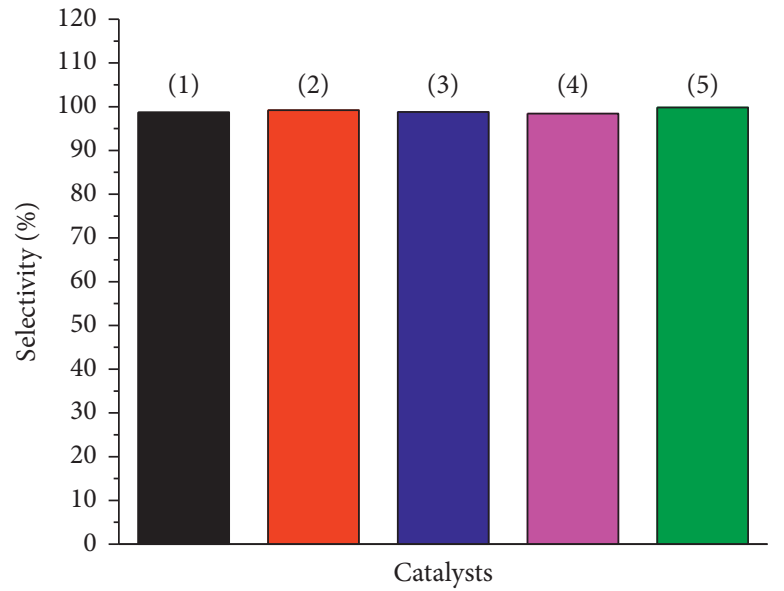

(b)

FIGURE 9: Effect of various ZIF-8 samples on the Knoevenagel condensation reaction: (a) benzaldehyde conversion (\%); (b) ethyl-2-cyano-3phenylacrylate selectivity ((1) without a catalyst; (2) Z-A(MeOH); (3) Z-B(DMF); (4) ZIF-8 sample synthesized with process A for five days; and (5) ZIF-8 sample synthesized with process $B$ at $\left.200^{\circ} \mathrm{C}\right)$.

TABLE 3: Effect of the different catalysts on Knoevenagel condensation.

\begin{tabular}{|c|c|c|c|c|}
\hline Catalyst & Precursors & Reaction condition & $\begin{array}{c}\text { Benzaldehyde } \\
\text { conversion (\%) }\end{array}$ & References \\
\hline ZIF-8* & $\begin{array}{l}\text { Benzaldehyde }(10 \mathrm{mmol}) \text { and } \\
\text { ethyl cyanoacetate }(10 \mathrm{mmol})\end{array}$ & $30^{\circ} \mathrm{C}, 6 \mathrm{~h}, 0.1 \mathrm{~g}$ of the catalyst & 76.5 & The present work \\
\hline ZIF-8 & $\begin{array}{l}\text { Benzaldehyde }(1.9 \mathrm{mmol}) \text { and } \\
\text { malononitrile }(1.9 \mathrm{mmol})\end{array}$ & $\begin{array}{c}\text { Room temperature, } 6 \mathrm{~h}, 0.02 \mathrm{~g} \text { of the } \\
\text { catalyst }\end{array}$ & 51 & [19] \\
\hline MCM-41 & $\begin{array}{l}\text { Benzaldehyde }(10 \mathrm{mmol}) \text { and } \\
\text { diethyl malonate }(10 \mathrm{mmol})\end{array}$ & $\begin{array}{c}\text { Room temperature, } 24 \mathrm{~h}, 0.025 \mathrm{~g} \text { of the } \\
\text { catalyst }\end{array}$ & $56-70$ & {$[16]$} \\
\hline Amine-MCM-41 & $\begin{array}{l}\text { Benzaldehyde }(10 \mathrm{mmol}) \text { and } \\
\text { diethyl malonate }(10 \mathrm{mmol})\end{array}$ & $\begin{array}{c}\text { Room temperature, } 24 \mathrm{~h}, 0.025 \mathrm{~g} \text { of the } \\
\text { catalyst }\end{array}$ & $78-92$ & {$[16]$} \\
\hline $\begin{array}{l}{\left[\mathrm{CTA}^{+}\right]-\mathrm{Si}-} \\
\mathrm{MCM}-41\end{array}$ & $\begin{array}{l}\text { Benzaldehyde }(4.8 \mathrm{mmol}) \text { and } \\
\text { ethyl cyanoacetate }(4.8 \mathrm{mmol})\end{array}$ & $30^{\circ} \mathrm{C}, 3 \mathrm{~h}, 20 \mathrm{mg}$ of the catalyst & 57.2 & {$[17]$} \\
\hline
\end{tabular}

*ZIF-8 sample synthesized with process $B$ at $200^{\circ} \mathrm{C}$.

into the reaction solution is found. Thus, in the ZIF- 8 sample synthesized with process $\mathrm{B}$ at $200^{\circ} \mathrm{C}$, the Lewis acid $\mathrm{Zn}^{2+}$ sites may become saturated; hence, the decrease in densities of the Lewis acid sites results in more base sites from the imidazole linkers.

A comparison of the benzaldehyde conversion of the Knoevenagel condensation with different catalysts is shown in Table 3. Although the reaction conditions are different, the benzaldehyde conversion of this study is higher $(76.5 \%$ compared with $51-70 \%$ ) or consistent with that of previous studies (78-92\%).

\section{Conclusions}

ZIF-8 was formed in methanol and water at room temperature and in DMF at high temperatures $\left(100-200^{\circ} \mathrm{C}\right)$. In methanol, the reaction time and meIm/Zn molar ratio have small effects on the microstructures (uniform particles of $\sim 100 \mathrm{~nm}$ diameter) of ZIF-8; however, the diffraction peaks at the angles smaller than $10^{\circ}$ had slight variations. In contrast, ZIF-8 synthesized in DMF manifests full crystallinity with varying particle sizes $(3 \sim 20 \mu \mathrm{m})$ with the better cohesion of particles observed at $200^{\circ} \mathrm{C}$. All ZIF-8 samples 
exhibit excellent catalytic activities in the Knoevenagel condensation reaction because of the base sites of imidazoles. When ZIF-8 are highly crystalline (samples synthesized in $\mathrm{MeOH}$ for five days and in DMF at $200^{\circ} \mathrm{C}$ ), the activities of the base sites of imidazole prevail those of the Lewis acid sites of $\mathrm{Zn}^{2+}$, resulting in a higher conversion of benzaldehyde.

\section{Data Availability}

The data used to support the findings of this study are available from the corresponding author upon request.

\section{Conflicts of Interest}

The authors declare that they have no conflicts of interest.

\section{References}

[1] H. Hayashi, A. P. Côté, H. Furukawa, M. O’Keeffe, and O. M. Yaghi, "Zeolite A imidazolate frameworks," Nature Materials, vol. 6, no. 7, pp. 501-506, 2007.

[2] K. S. Park, Z. Ni, A. P. Cote et al., "Exceptional chemical and thermal stability of zeolitic imidazolate frameworks," Proceedings of the National Academy of Sciences, vol. 103, no. 27, pp. 10186-10191, 2006.

[3] X. C. Huang, Y. Y. Lin, J. P. Zhang, and X. M. Chen, "Liganddirected strategy for zeolite-type metal-organic frameworks: zinc(II) imidazolates with unusual zeolitic topologies," Angewandte Chemie International Edition, vol. 45, no. 10, pp. 1557-1559, 2006.

[4] Y. He, W. Zhou, G. Qian, and B. Chen, "Methane storage in metal-organic frameworks," Chemical Society Reviews, vol. 3, no. 16, pp. 5657-5678, 2014.

[5] E. Barea, C. Montoro, and J. A. R. Navarro, "Toxic gas removal-metal-organic frameworks for the capture and degradation of toxic gases and vapours," Chemical Society Reviews, vol. 45, no. 43, 2014.

[6] M. Hu, H. Lou, X. Yan, X. Hu, R. Feng, and M. Zhou, "In-situ fabrication of ZIF-8 decorated layered double oxides for adsorption and photocatalytic degradation of methylene blue," Microporous and Mesoporous Materials, vol. 271, pp. 68-72, 2018.

[7] V. Stavila, A. A. Talin, and M. D. Allendorf, "MOF-based electronic and opto-electronic devices," Chemical Society Reviews, vol. 43, no. 16, pp. 5994-6010, 2014.

[8] D. Q. Khieu, M. T. Thanh, T. V. Thien et al., "Synthesis and voltammetric determination of $\mathrm{Pb}$ (II) using a ZIF-8-based electrode," Journal of Chemistry, vol. 2018, Article ID 5395106, 12 pages, 2018.

[9] P. Horcajada, R. Gref, T. Baati et al., "Metal-organic frameworks in biomedicine," Chemical Reviews, vol. 112, no. 2, pp. 1232-1268, 2012.

[10] S. R. Venna, J. B. Jasinski, and M. A. Carreon, "Structural evolution of zeolitic imidazolate framework-8," Journal of the American Chemical Society, vol. 132, no. 51, pp. 18030-18033, 2010.

[11] J. Cravillon, C. A. Schröder, H. Bux, A. Rothkirch, J. Caro, and M. Wiebcke, "Formate modulated solvothermal synthesis of ZIF-8 investigated using time-resolved in situ X-ray diffraction and scanning electron microscopy," CrystEngComm, vol. 14, no. 2, pp. 492-498, 2012.

[12] M. Zhu, S. R. Venna, J. B. Jasinski, and M. A. Carreon, "Roomtemperature synthesis of ZIF-8: the coexistence of $\mathrm{ZnO}$ nanoneedles," Chemistry of Materials, vol. 23, no. 16, pp. 3590-3592, 2011.

[13] M. T. Thanh, T. V. Thien, P. D. Du, N. P. Hung, and D. Q. Khieu, "Iron doped zeolitic imidazolate framework (FeZIF-8): synthesis and photocatalytic degradation of RDB dye in Fe-ZIF-8," Journal of Porous Materials, vol. 25, no. 3, pp. 857-869, 2018.

[14] D. N. Ta, H. K. D. Nguyen, B. X. Trinh, Q. T. N. Le, H. N. Ta, and H. T. Nguyen, "Preparation of nano-ZIF-8 in methanol with high yield," Canadian Journal of Chemical Engineering, vol. 96, no. 7, pp. 1518-1531, 2018.

[15] P. Formentín, H. García, and A. Leyva, "Assessment of the suitability of imidazolium ionic liquids as reaction medium for base-catalysed reactions Case of Knoevenagel and ClaisenSchmidt reactions," Journal of Molecular Catalysis A: Chemical, vol. 214, no. 1, pp. 137-142, 2004.

[16] K. M. Parida and D. Rath, "Amine functionalized MCM-41: an active and reusable catalyst for Knoevenagel condensation reaction," Journal of Molecular Catalysis A: Chemical, vol. 310, no. 1-2, pp. 93-100, 2009.

[17] L. Martins, W. Hölderich, P. Hammer, and D. Cardoso, "Preparation of different basic Si-MCM-41 catalysts and application in the Knoevenagel and Claisen-Schmidt condensation reactions," Journal of Catalysis, vol. 271, no. 2, pp. 220-227, 2010.

[18] L. Martins, T. J. Bonagamba, E. R. de Azevedo, P. Bargiela, and D. Cardoso, "Surfactant containing Si-MCM-41: an efficient basic catalyst for the Knoevenagel condensation," Applied Catalysis A: General, vol. 312, pp. 77-85, 2006.

[19] U. P. N. Tran, K. K. A. Le, and N. T. S. Phan, "Expanding applications of metal-organic frameworks: zeolite imidazolate framework ZIF-8 as an efficient heterogeneous catalyst for the Knoevenagel reaction," ACS Catalysis, vol. 1, no. 2, pp. 120127, 2011

[20] M. Zhu, D. Srinivas, S. Bhogeswararao, P. Ratnasamy, and M. A. Carreon, "Catalytic activity of ZIF-8 in the synthesis of styrene carbonate from $\mathrm{CO}_{2}$ and styrene oxide," Catalysis Communications, vol. 32, pp. 36-40, 2013.

[21] A. F. Bushell, M. P. Attfield, C. R. Mason et al., "Gas permeation parameters of mixed matrix membranes based on the polymer of intrinsic microporosity PIM-1 and the zeolitic imidazolate framework ZIF-8," Journal of Membrane Science, vol. 427, pp. 48-62, 2013.

[22] J. Yao, R. Chen, K. Wang, and H. Wang, "Direct synthesis of zeolitic imidazolate framework-8/chitosan composites in chitosan hydrogels," Microporous and Mesoporous Materials, vol. 165, pp. 200-204, 2013.

[23] X. Zhou, H. P. Zhang, G. Y. Wang, Z. G. Yao, Y. R. Tang, and S. S. Zheng, "Zeolitic imidazolate framework as efficient heterogeneous catalyst for the synthesis of ethyl methyl carbonate," Journal of Molecular Catalysis A: Chemical, vol. 366, pp. 43-47, 2013.

[24] Y. Zhang, Y. Jia, M. Li, and L. Hou, "Influence of the 2methylimidazole/zinc nitrate hexahydrate molar ratio on the synthesis of zeolitic imidazolate framework- 8 crystals at room temperature," Scientific Reports, vol. 8, no. 1, pp. 1-7, 2018.

[25] K. Kida, M. Okita, K. Fujita, S. Tanaka, and Y. Miyake, "Formation of high crystalline ZIF-8 in an aqueous solution," CrystEngComm, vol. 15, no. 9, p. 1794, 2013.

[26] Y. Du, R. Z. Chen, J. F. Yao, and H. T. Wang, "Facile fabrication of porous $\mathrm{ZnO}$ by thermal treatment of zeolitic imidazolate framework-8 and its photocatalytic activity," Journal of Alloys and Compounds, vol. 551, pp. 125-130, 2013. 


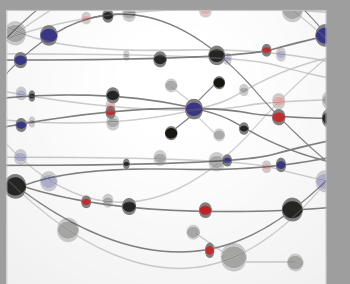

The Scientific World Journal
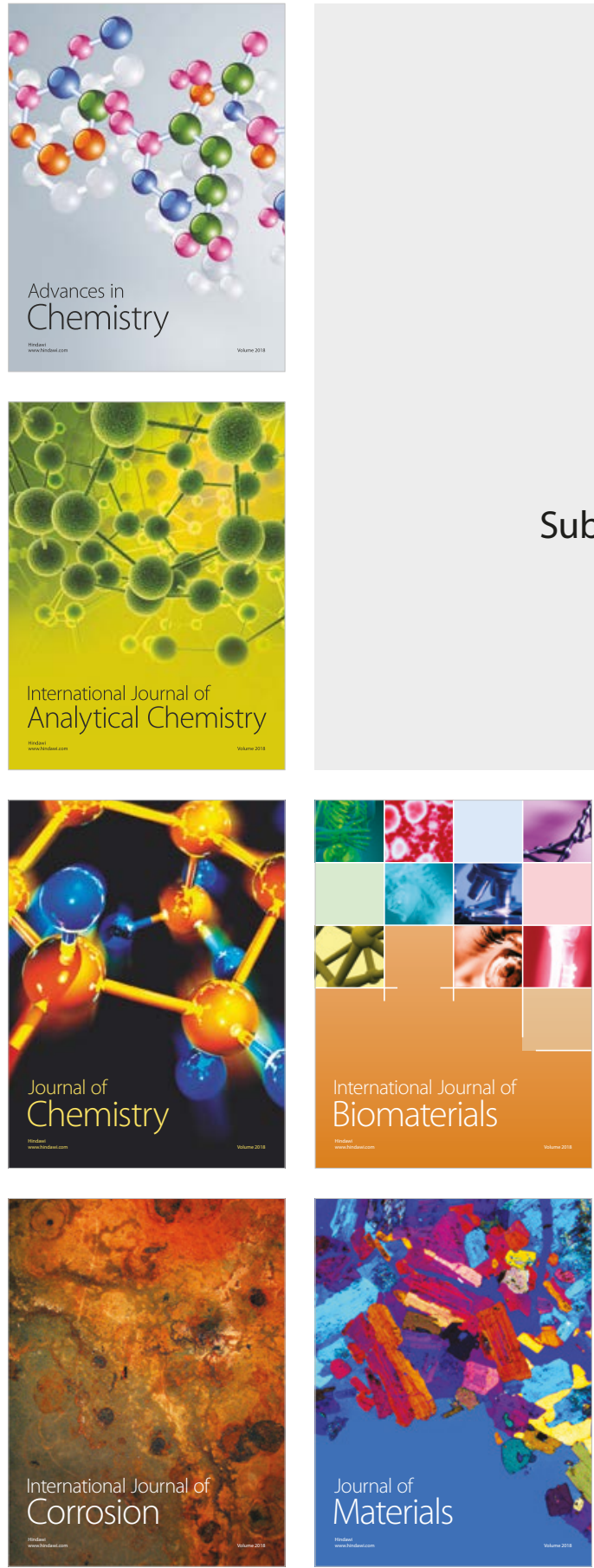

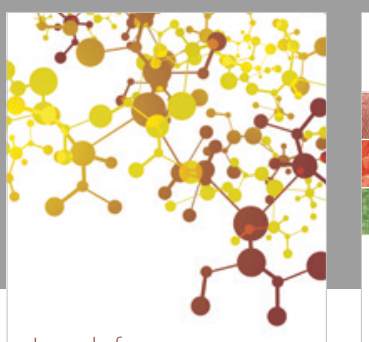

Journal of

Applied Chemistry
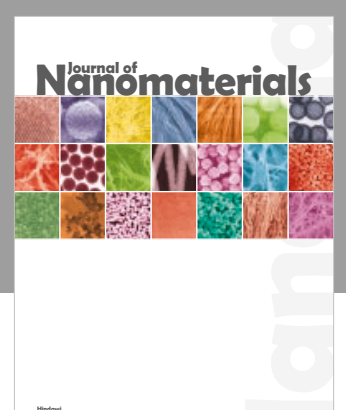

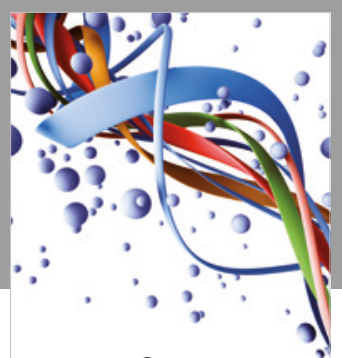

Scientifica

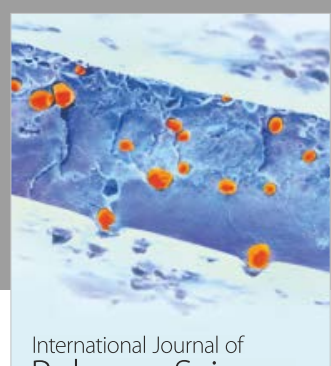

Polymer Science

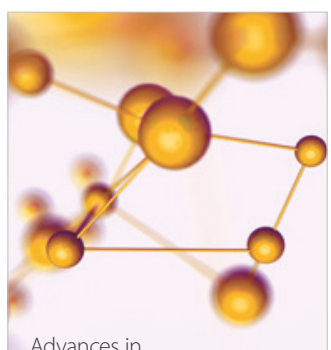

Physical Chemistry
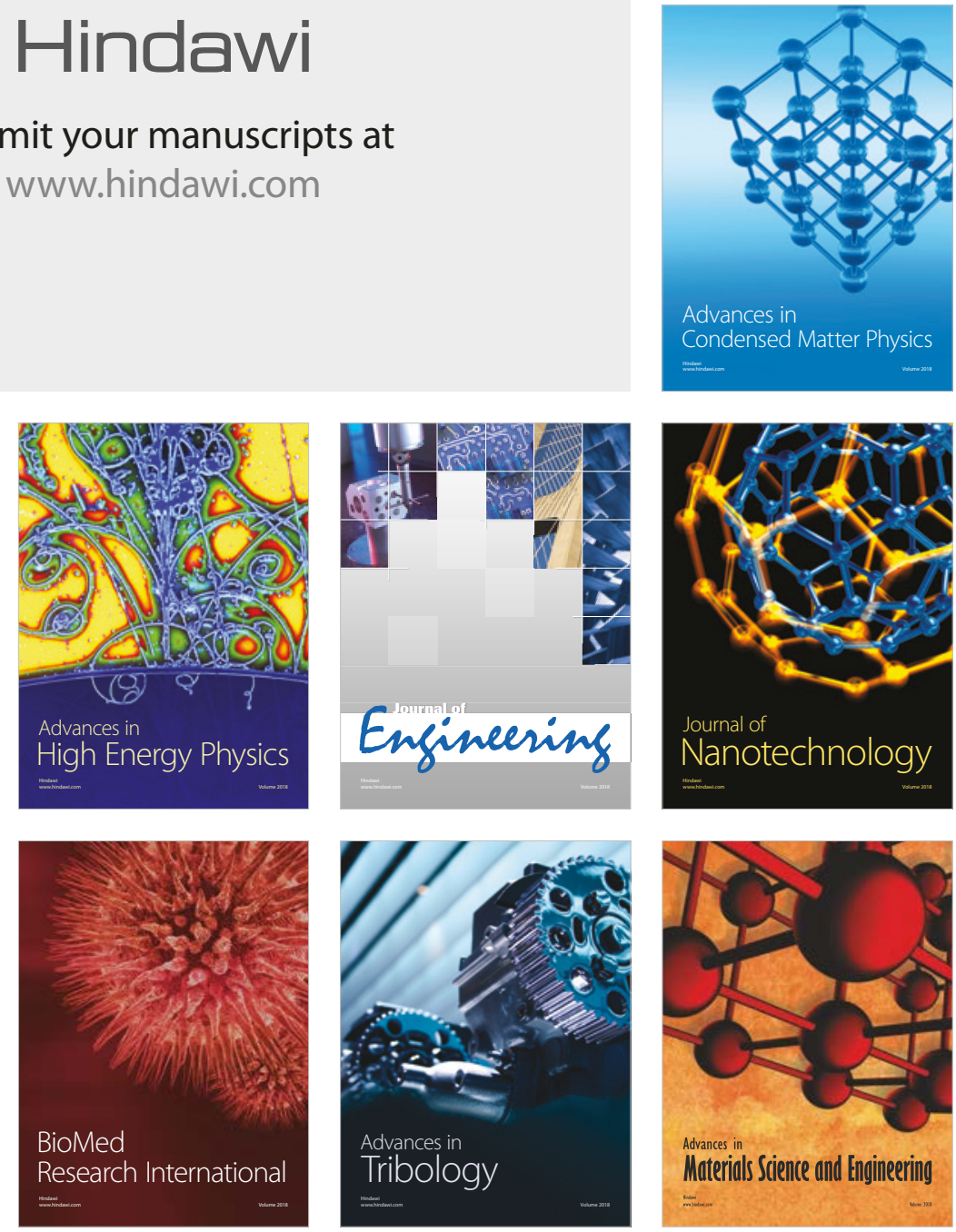